\title{
Micro Controller Based Ac Power Controller
}

\author{
S. A. HARI PRASAD ${ }^{1}$, B. S. KARIYAPPA ${ }^{1}$, R. NAGARAJ ${ }^{2}$, S. K.THAKUR ${ }^{3}$ \\ ${ }^{1}$ Department of Electronics \& Communication Engineering, R.V. College of Engineering, Bangalore, India \\ ${ }^{2}$ Director, Center for Cognitive Technologies,R.V.C.E. Campus, Bangalore, India \\ ${ }^{3}$ Deputy Director, Naval Research Board, Defence Research Development Organization, New-Delhi, India \\ Email: harivat2002@yahoo.co.in \\ Received April 25, 2009; revised May 8, 2009; accepted May 9, 2009
}

\begin{abstract}
This paper discusses the design and implementation of single phase PWM inverter using 8051 microcontroller. The main features of 8051 based PWM inverter are simpler design, low cost, maximum range of voltage control and compact in size. The designed PWM inverter is tested on various AC loads like AC motor and intensity control of incandescent lamp in a closed loop environment.
\end{abstract}

Keywords: Gate Signals Generation, Micro Controller, Pulse Width Modulation, PWM Generation

\section{Introduction}

The pulse width inverters can be broadly classified as

$>$ Analog bridge PWM inverter [1]

$>$ Digital bridge PWM inverters [2]

The advantage of Analog based PWM inverter controller is that, the level of inverter output voltage can be adjusted in a continuous range and the throughput delay is negligible. The disadvantages of Analog based PWM inverters are:

Analog component output characteristics changes with the temperature and time. They are prone to external disturbances. Analog controller circuitry is complex and bulky. They are non-programmable, hence not flexible.

On the other hand Microcontroller based PWM inverter controller (Digital bridge PWM inverter) makes the controller free from disturbances and drift, but the performance is not very much high due to its speed limitation. However to minimize throughput delay, some microcontroller based PWM inverters, retrieves switching patterns directly from memory so that calculation can be minimized, but this technique demands more memory. This drawback can be eliminated if switching patterns are generated by executing simple control algorithms [3]. Even after using simple control algorithms, sometimes throughput delay may be substantial.

With the availability of advanced microcontrollers and DSP [Digital signal processor] controllers [4], with many advanced features like inbuilt PWM generator, event managers, time capture unit, dead time delay generators, watch dog timers along with high clock frequency, the limitation of speed, associated with microcontroller based PWM inverters [5] can be neglected to some extent.

This paper presents a simple and cost effective technique of implementing single-phase AC [alternating current] voltage controller, used to control AC loads, which doesn't demand very high precisions, using 8051 microcontroller.

The paper is organized as follows.

$>$ Review of PWM inverters.

$>$ Block diagram of controller.

$>$ Controller implementation (software and hardware).

$>$ Results and Conclusion.

\section{PWM Bridge Inverter Review}

Inverters can be classified as single-phase and three phase inverters [6] and they are further classified as Voltage fed inverter [VSI.], current fed inverter [CFI], and variable DC [direct current] linked inverter. In Voltage fed inverter, input voltage remains constant, in current fed inverter [CFI], input current remains constant and in variable DC [direct current] linked inverter, input voltage is controllable. 


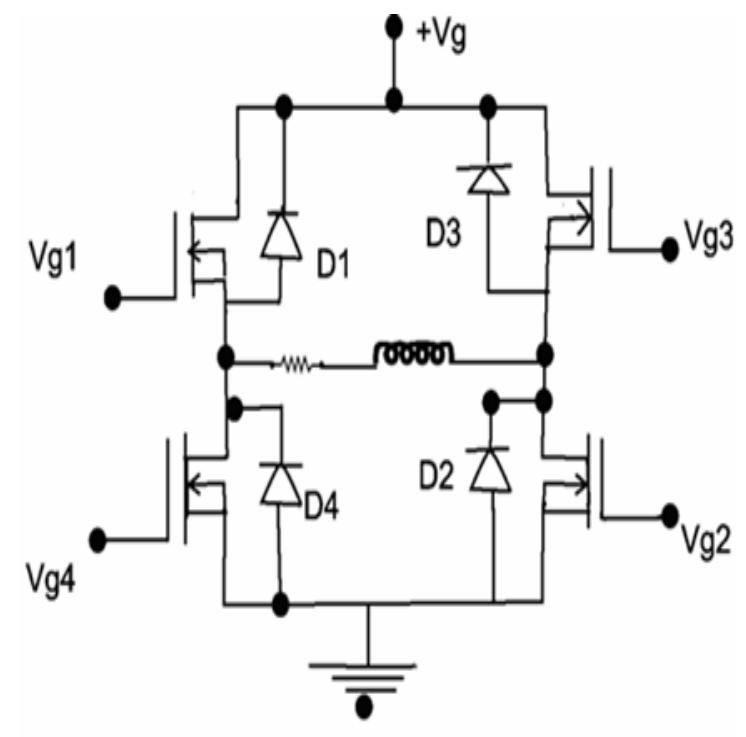

Figure 1. Single phase inverter.

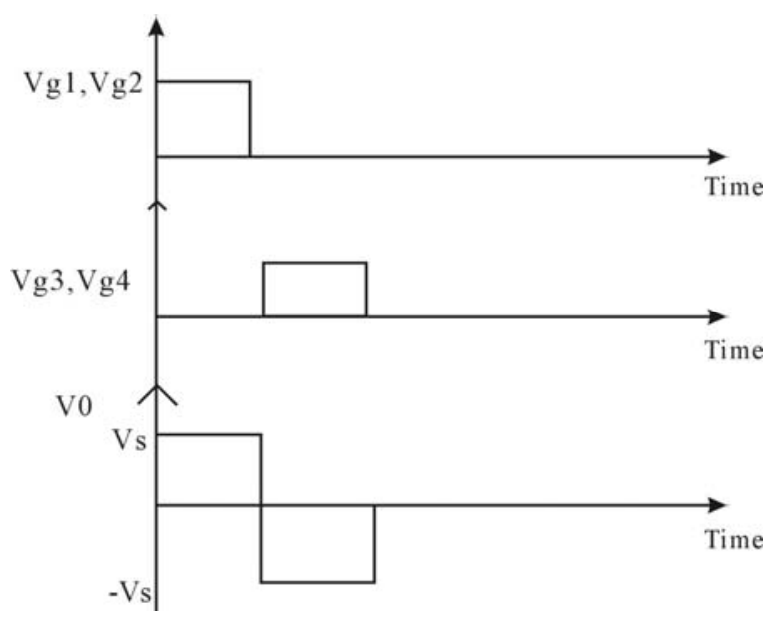

Figure 2. O/P voltage/gate signals.
Figure 1 shows single phase bridge inverter with MOSFET switches [6]. In spite of MOSFET switches having high $\mathrm{ON}$ state resistance and conduction losses [7], in this paper MOSFET switches are used because of the following reasons. MOSFET being a voltage controlled device, it can be driven directly from CMOS or TTL logic and the same gate signal can be applied to diagonally opposite switches. Also the gate drive current required is very low [7].

The working principle of Single-phase bridge inverter can be explained as follows.

Positive Voltage 'Vs' appears across the load, when MOSFET Q1 and Q2 conduct simultaneously. Negative voltage 'Vs' appears across the load, when Q3 and Q4 conduct simultaneously.

To overcome the effect of back emf in case of inductive load diodes, D1-D4 are used. Diode D1 and D2 are called feedback diodes, because when they conduct the energy is feedback to the DC source. The RMS output voltage is given by

$$
V_{o}=V_{s} \sqrt{p / \Pi}
$$

where $\mathrm{P}$ is pulse width. The $\mathrm{O} / \mathrm{P}$ voltage and gate signals are as shown in Figure 2.

\section{Controller Block Diagram}

The block diagram of microcontroller based bridge PWM inverter is as shown in Figure 3. The required four digit speed in RPM [Rotation per Minute] is entered through the keyboard and corresponding to the key pressed, digital equivalent of that RPM is stored in memory.

Current running speed of the AC motor is sensed through speed sensor, and the analog output given by the sensor is converted to digital data using Analog to Digital converter $[\mathrm{ADC}]$.

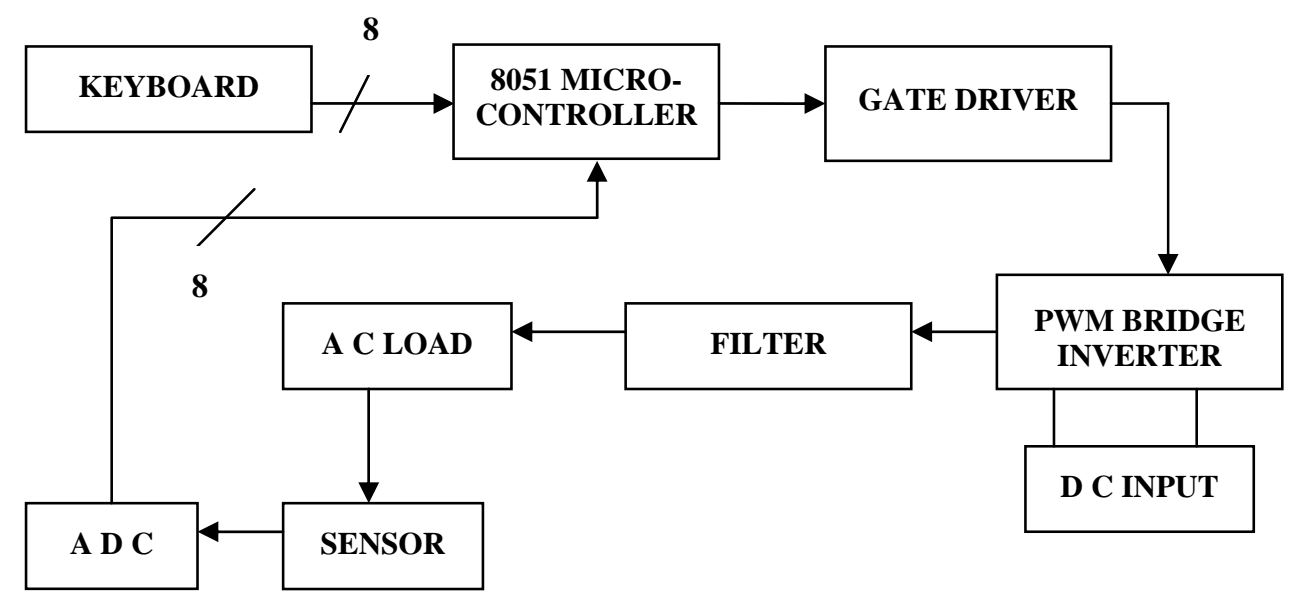

Figure 3. Block diagram of controller. 


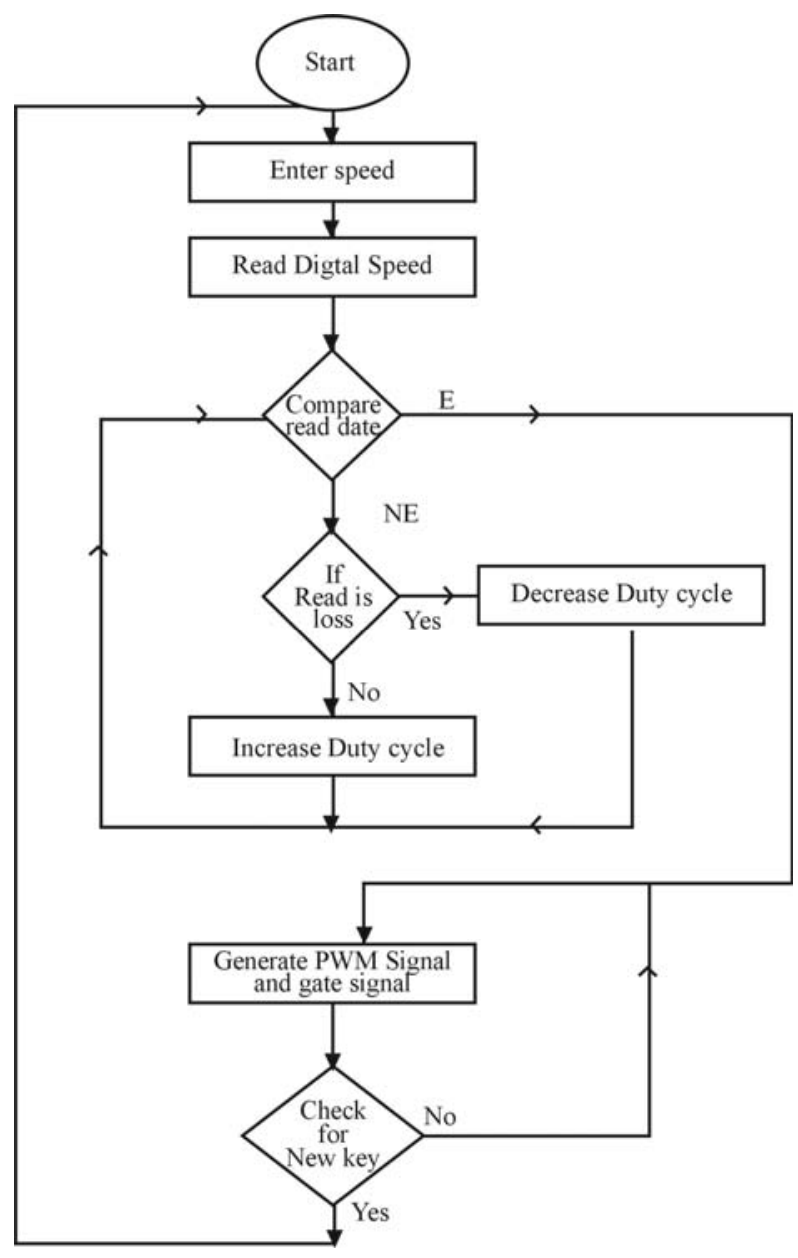

Figure 4. Flowchart of basic operation.

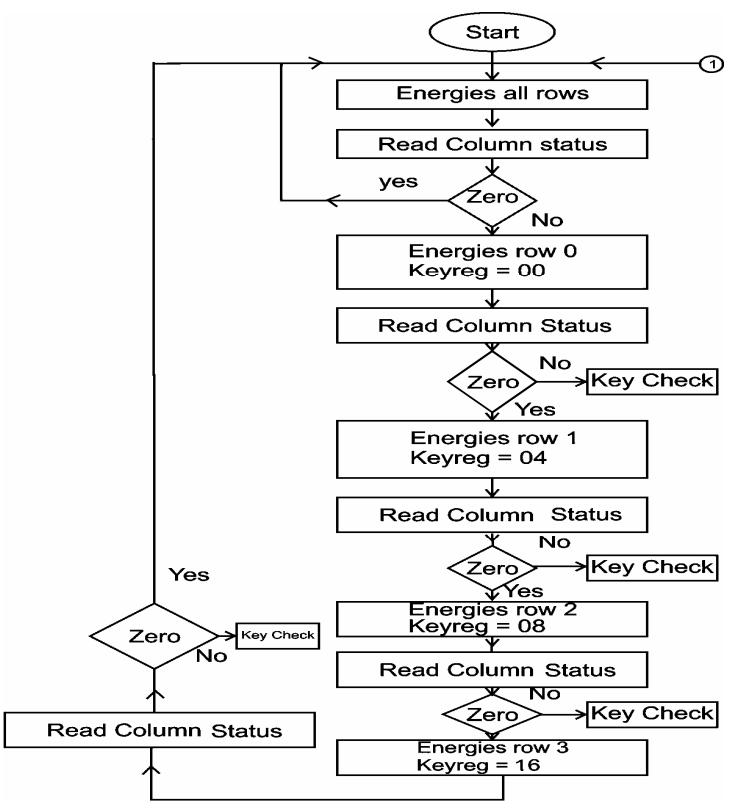

Figure 5. Flow chart of keyboard logic.

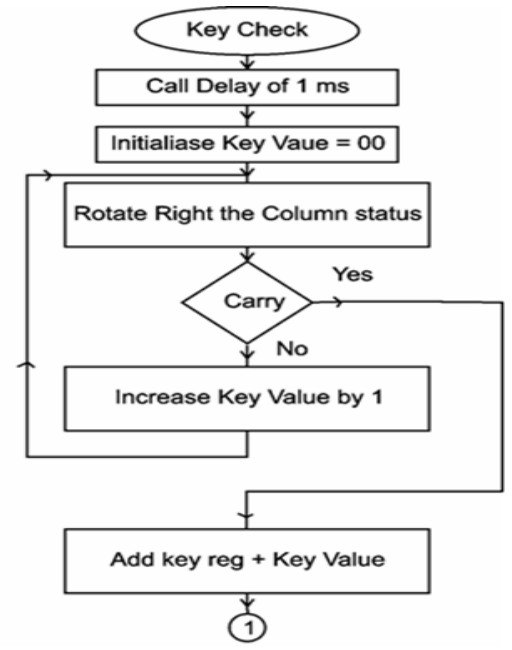

Figure 6. Flowchart of keyboard logic.

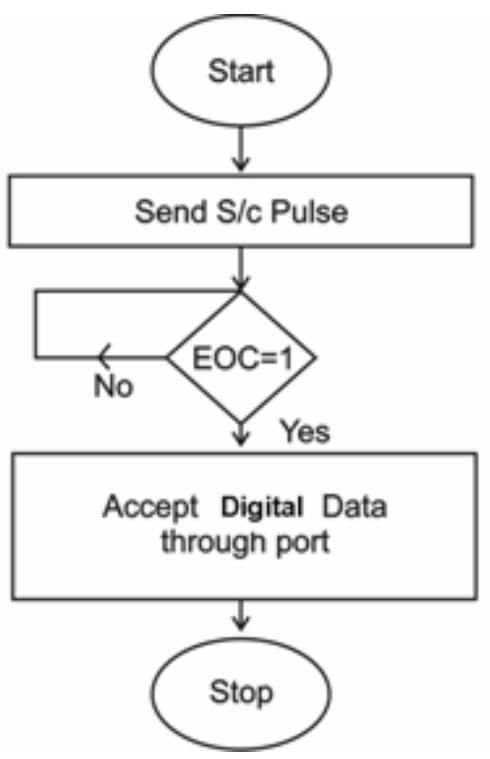

Figure 7. Flowchart of A/D converter.

The digital data is accepted through 8051 microcontroller ports and is compared with required speed's equivalent digital data. In accordance with the error signal, the width (duty cycle) of PWM signal is varied, which in turn controls the AC voltage.

From the generated PWM signal, required two gate signals are generated using external interrupt to drive the bridge inverter circuit.

Gate signals are boosted up to a sufficient voltage level by using gate driver circuit, so that it can drive the MOSFET switches of bridge inverter to the ON state. User can alter the speed at any instant of time in accordance to his requirements. Many additional features can be further added like sensing the temperature of room and automatically controlling either the speed of 
the fan or the level of air conditioning required. Figure 4 explains the logic flow of the basic operation.

\section{Controller Design}

Controller is designed by using simpler low cost components like 8051 microcontroller, 8 or 12 bit Analog to Digital Converter (ADC), $4 \times 4$ keypad, 4 chopper MOSFET switches (IRFZ48) and speed/Intensity sensor.

The controller design can be explained under 4 sections as:

Keypad interface with $8051 \mu \mathrm{c}$.

ADC interface with $\mu \mathrm{c}$.

Generating PWM signals and gate signals using 8051 microcontroller.

$>$ Gate driver circuit implementation.

\subsection{Keypad Interface}

A $4 \times 4$ keypad is interface with 8051 microcontroller as shown in Figure 5, through which four keys are accepted. After accepting the four keys they are combined to represent four digit required RPM, which actually represents the external memory address, in which digital equivalent of speed is stored.

For example if the keys entered are 1 (01), 2 (02), 3 (03), 4 (04), then they are combined as 1234 (RPM), which represents External memory address, in which 8 bit digital equivalent of that speed is stored. Higher byte of the memory address is stored in DPH [data pointer high byte]. Lower byte of the memory address is stored in DPL [data pointer low byte]. This method saves time since it doesn't require any program execution to convert the entered speed in RPM into its digital equivalent. The other method is to enter equivalent digital data of RPM directly, provided a conversion chart is available [external look-up table]. This technique will save some memory access time, since communication with memory is avoided.

\subsection{ADC Interfacing}

Whenever speed varies from zero to maximum, the speed sensor $\mathrm{O} / \mathrm{P}$ varies from zero to five volts respectively. An 8-bit ADC with resolution $1 / 2^{8}$ is used to convert the analog voltage to digital data. Minimum of $19.5 \mathrm{mv}$ change in voltage (corresponding change in RPM) is required to change the digital state of ADC. This limits the accuracy of the application. The logic of interfacing $\mathrm{ADC}$ is as explained in the flowchart given in the Figure 7.

\subsection{PWM Generation}

8051 microcontroller do not have on-chip PWM generator. It is implemented using ' $A$ ' register and any other register (R0-R7) as shown in Figure 8.

A count (ON period time) is loaded onto one of the GPR (General purpose register), which can be called as Duty cycle register and accumulator ('A') is loaded with zero. Register ' $A$ ' is incremented in steps of one and continuously compared with duty cycle register.

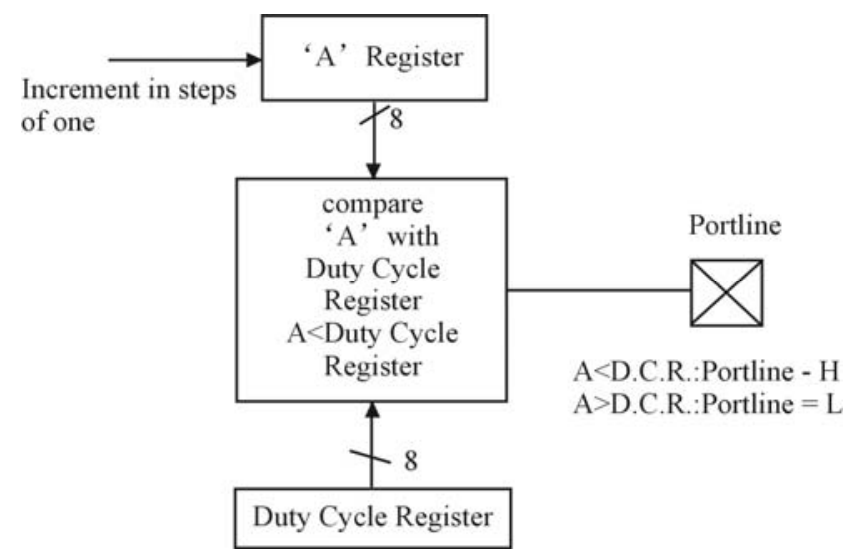

Figure 8. PWM generation.
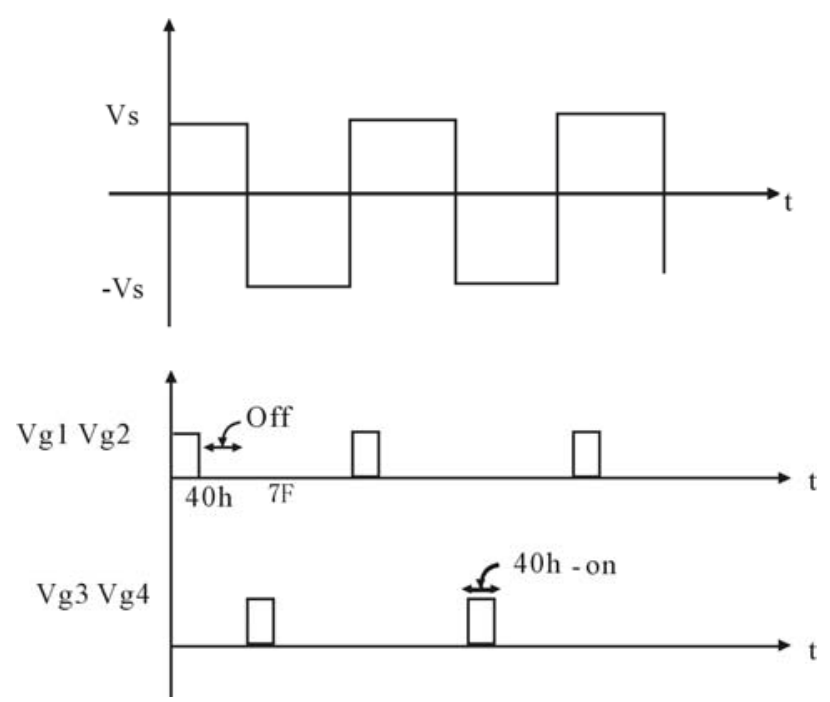

Figure 9. Gate signal generation using interrupt.

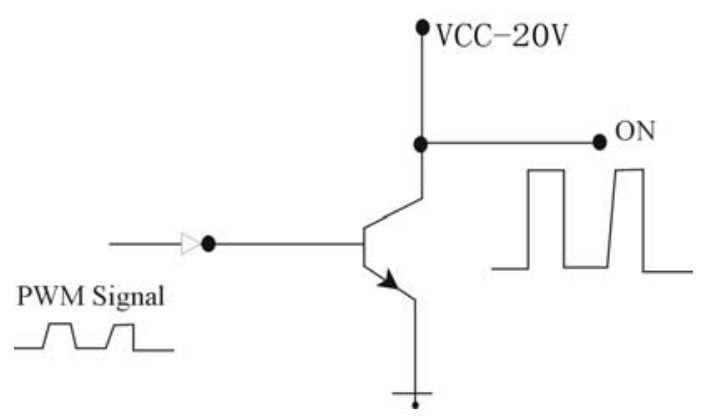

Figure 10. Gate signal booster circuit. 

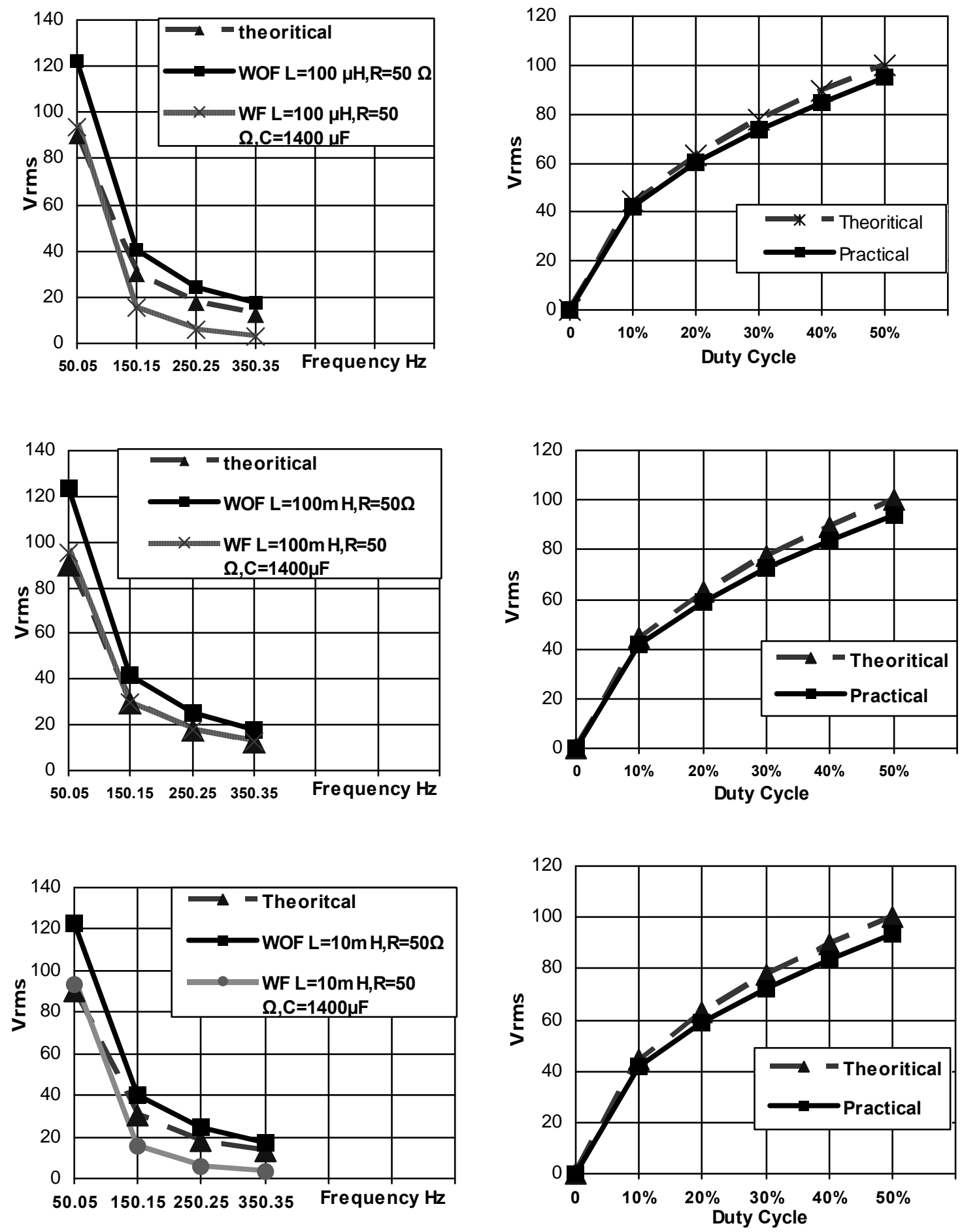

Figure 11. Response for various loads with corresponding duty cycles.

If the ' $\mathrm{A}$ ' contents are less than duty cycle register, high level is maintained at port line P1.1. When ' $\mathrm{A}$ ' is higher than duty cycle register content a low level is maintained on port line. The alternate technique is to use Timer as Counter by applying clock pulses externally and comparing the count present in the counter with ' $\mathrm{A}$ ' register (duty cycle register). This demands external clock source, since 8051 do not have any clock out pin.

Since the maximum time period is limited to $256 \mathrm{mi}-$ croseconds, the minimum frequency of PWM signal will 
be $4 \mathrm{KHz}$, but this can be changed using software delays. The AC signal frequency generated by PWM bridge inverter depends on PWM signal frequency. The error signal is generated by comparing the required speed with accepted digital equivalent speed divided by two. In proportionate with the error signal, PWM duty cycle is varied. When the required speed value is less than the accepted one, duty cycle register value and accepted value is decremented by one continuously till accepted value is equal to the required speed's digital value. When the required speed value is more than the accepted one, duty cycle register values and accepted value is incremented by one continuously till accepted value is equal to the required speed digital values.

\subsection{Gate Signal Generation}

The generated controlled PWM signal itself will be one set of gate signal $\left(\mathrm{g}_{1}, \mathrm{~g}_{2}\right)$ and other set of gate signals $\left(\mathrm{g}_{3}\right.$, $\left.\mathrm{g}_{4}\right)$ is generated using interrupt technique. The controlled PWM signal generated is given to the external interrupts, which is initialized as falling edge sensitive interrupt type. When controlled PWM signal's falling edge occurs, an interrupt service routine meant for that particular external interrupt is executed.

In the interrupt service routine, a delay is created equal to the time, 7FH minus duty cycle register content, after which, the port line is made high and is retained high for the time duration decided by the contents of duty cycle register (Figure 9).

The gate signal $\left(\operatorname{vg}_{1} \operatorname{vg}_{2}, \operatorname{vg}_{3}, \operatorname{vg}_{4}\right)$ are boosted to a sufficient voltage level by Gate drive circuitry as shown in Figure 10, so that they are capable of driving MOSFET'S to the ON state, when the gate signals are high.

A transistor switch (with inverted gate signals as input) is made used to boost the gate signal. The same DC supply, which is used for inverter is also used to drive the transistor by reducing the DC level using voltage dividers. The other technique is to use opto-isolators. Both of these techniques use the same inverter DC source to boost up the gate signals, thus avoiding more usage of DC sources.

\section{Results and Conclusions}

The designed application is tested by designing $60 \mathrm{~V}$
MOSFET bridge inverter.

Harmonics are removed by using simple capacitor filter and the AC voltage is stepped up to $220 \mathrm{~V}$ using step-up transformer. The performance of application is tested on various A.C loads and the plots of the same are as shown in Figure 10. The design exhibits good results for the load values of $50 \mathrm{ohm}$ and $100 \mathrm{mH} / 10 \mathrm{mH}$. A simple PWM technique with $100 \%$ duty cycle variation, which reduces hardware and software complexity, is used rather than using the most often used complex sinusoidal PWM technique (For Single-phase inverters). Required dead time is generated through interrupt, which avoids the usage of dead time delay generators. With minor modifications the same work can be used to control light intensity, temperature etc., The accuracy can be further improved by using high resolution ADC's and the delay involved in the software can be overcome using higher versions of controllers.

\section{References}

[1] H. Parasuram and B. Ramaswami, "A three phase sine wave reference generator for thyristorized motor controllers," IEEE Transactions on Industrial Electronics, Vol. IE-23, pp. 270-276, August 1976.

[2] J. M. D. Murphy, L. S. Howard, and R. G. Hoft, "Microprocessor control of PWM inverter induction motor drive," in Record of the 1979 IEEE Power Electron Specialist Conference, pp. 344-348.

[3] G. S. Buja and P. Fiorini, "Microcomputer control of PWM inverters," IEEE Transactions on Industrial Electronics, Vol. IE-29, pp. 212-216, August 1982.

[4] G. S. Buja and P. De Nardi, "Application of a signal processor in PWM inverter control," IEEE Transactions on Industrial Electronics, Vol. IE-32, No. 1, February 1985.

[5] Y. K. Peng, et al., "A novel PWM technique in digital control," IEEE Transactions on Industrial Electronics, Vol. 54, February 2007.

[6] M. H. Rashid, "Power Electronics Circuits, Devices and Applications," 3rd Edition, Prentice-Hall of India, Private limited, New-Delhi, 2004.

[7] V. Jagannathan, "Introduction to power electronics," Prentice-Hall of India, Private limited, New-Delhi, 2006. 